\title{
Anaerobic energy provision does not limit Wingate exercise performance in endurance-trained cyclists
}

\author{
J. A. L. CALBET, ${ }^{1}$ J. A. DE PAZ, ${ }^{2}$ N. GARATACHEA, ${ }^{2}$ \\ S. CABEZA DE VACA, ${ }^{3}$ AND J. CHAVARREN ${ }^{1}$ \\ ${ }^{1}$ Department of Physical Education, University of Las Palmas de Gran Canaria, \\ 35017 Las Palmas de Gran Canaria, Canary Islands; ${ }^{2}$ Instituto Nacional de \\ Educación Física de Leon, University of Leon, 24071 Leon; and ${ }^{3}$ Centro de \\ Tecnificación de Ciclismo, Chiclana de la Frontera, 11130 Cádiz, Spain
}

Submitted 20 February 2002; accepted in final form 1 October 2002

\begin{abstract}
Calbet, J. A. L., J. A. De Paz, N. Garatachea, S. Cabeza de Vaca, and J. Chavarren. Anaerobic energy provision does not limit Wingate exercise performance in endurance-trained cyclists. J Appl Physiol 94: 668-676, 2003. First published October 4, 2002; 10.1152/japplphysiol.00128. 2002.-The aim of this study was to evaluate the effects of severe acute hypoxia on exercise performance and metabolism during 30-s Wingate tests. Five endurance- (E) and five sprint- (S) trained track cyclists from the Spanish National Team performed 30-s Wingate tests in normoxia and hypoxia (inspired $\mathrm{O}_{2}$ fraction $=0.10$ ). Oxygen deficit was estimated from submaximal cycling economy tests by use of a nonlinear model. E cyclists showed higher maximal $\mathrm{O}_{2}$ uptake than $\mathrm{S}$ $\left(72 \pm 1\right.$ and $\left.62 \pm 2 \mathrm{ml} \cdot \mathrm{kg}^{-1} \cdot \mathrm{min}^{-1}, P<0.05\right)$. S cyclists achieved higher peak and mean power output, and 33\% larger oxygen deficit than E $(P<0.05)$. During the Wingate test in normoxia, $\mathrm{S}$ relied more on anaerobic energy sources than $\mathrm{E}(P<0.05)$; however, $\mathrm{S}$ showed a larger fatigue index in both conditions $(P<0.05)$. Compared with normoxia, hypoxia lowered $\mathrm{O}_{2}$ uptake by $16 \%$ in $\mathrm{E}$ and $\mathrm{S}(P<0.05)$. Peak power output, fatigue index, and exercise femoral vein blood lactate concentration were not altered by hypoxia in any group. Endurance cyclists, unlike S, maintained their mean power output in hypoxia by increasing their anaerobic energy production, as shown by $7 \%$ greater oxygen deficit and $11 \%$ higher postexercise lactate concentration. In conclusion, performance during 30-s Wingate tests in severe acute hypoxia is maintained or barely reduced owing to the enhancement of the anaerobic energy release. The effect of severe acute hypoxia on supramaximal exercise performance depends on training background.
\end{abstract}

fatigue; anaerobic power; anaerobic capacity; lactate

THE IMPACT THAT ACUTE SEVERE hypoxia has on aerobic and anaerobic energy yield during the Wingate test remains unknown. Although moderate acute hypoxia [inspired $\mathrm{O}_{2}$ fraction $\left(\mathrm{F}_{\mathrm{O}_{2}}\right)=0.13$ ] has no effect on either $\mathrm{O}_{2}$ uptake $\left(\dot{\mathrm{V}}_{2}\right)$ or performance during supramaximal exercise of a duration up to $30 \mathrm{~s}$ (39), conflicting results have been reported about the influence that

Address for reprint requests and other correspondence: J. A. L. Calbet, Departamento de Educación Física, Universidad de Las Palmas de Gran Canaria, Campus Universitario de Tafira, 35017 Las Palmas de Gran Canaria, Canary Islands, Spain (E-mail: lopezcalbet@terra.es). higher levels of hypoxia might have on performance and metabolism $(22,23)$. McLellan et al. (23) observed unchanged mean power output (Pmean) and $\dot{\mathrm{V}}_{2}$ during a 30-s Wingate test performed with a $\mathrm{F}_{\mathrm{I}_{2}} \sim 0.11$. Prolonging the Wingate test duration until 45 s consistently resulted in lower $\mathrm{VO}_{2}$ with hypoxia $(22,23)$ whereas, compared with normoxia, Pmean during the 45-s Wingate test was not affected by acute hypoxia in one study (23) and slightly reduced ( $\sim 3 \%$ less) in another investigation (23). Small differences in the $\mathrm{FI}_{\mathrm{I}_{2}}$ and time exposure to hypoxia before the start of the Wingate tests could explain the apparently contradictory results reported by McLellan et al. $(22,23)$. It was clearly shown, on the other hand, that during all-out exercise in acute hypoxia lasting 30 or $45 \mathrm{~s}$, muscle lactate accumulation is markedly increased, indicating a greater anaerobic energy release with acute hypoxia (23). Furthermore, some pieces of evidence suggest that during supramaximal exercise producing exhaustion between 30 and $60 \mathrm{~s}$ the contribution of the anaerobic energy sources is increased in acute moderate hypoxia $(22,39)$. Whether a higher degree of hypoxia could enhance anaerobic energy release during 30 -s Wingate tests is not known.

It has been estimated that, in general, anaerobic energy sources provide 70-80\% of energy utilized throughout the Wingate test $(6,28,33,40)$. However, compared with sprint specialists, endurance-trained athletes have greater mean $\dot{\mathrm{V}}_{2}$ during the Wingate tests (12) and obtain a higher fraction of the energy from oxidative metabolism. In turn, sprint-trained athletes obtain a greater fraction of energy through the anaerobic pathways (6). Thus it can be hypothesized that because endurance-trained athletes rely more on aerobic energy sources to perform all-out supramaximal exercise they will experience a relatively greater impairment of performance than sprint-trained athletes with acute hypoxia, unless they compensate for the reduction in $\mathrm{V}_{2}$ by enhancing the anaerobic energy release.

The costs of publication of this article were defrayed in part by the payment of page charges. The article must therefore be hereby marked "advertisement" in accordance with 18 U.S.C. Section 1734 solely to indicate this fact. 
Therefore, the primary aim of this study was to find out whether the reduction in $\mathrm{O}_{2}$ supply elicited by severe acute hypoxia can be counteracted by enhancing anaerobic energy production during $30-\mathrm{s}$ Wingate tests. Another purpose was to verify whether endurance-trained elite track cyclists would experience superior deterioration of performance than their sprinttrained counterparts during 30 -s Wingate tests in acute hypoxia. To unravel more easily the effect of hypoxia, the $\mathrm{FI}_{\mathrm{O}_{2}}$ was reduced to 0.104 , which is equivalent to an altitude of $\sim 5,300 \mathrm{~m}$. This level of hypoxia is close to the limit that a healthy nonacclimatized human can tolerate acutely during upright exercise (4, $32,36)$.

\section{METHODS}

\section{Subjects}

This study was approved by the ethics committee at the University of Las Palmas de Gran Canaria. The subjects were fully informed of the purpose and possible risks and benefits of their participation in the study before giving their written consent. Ten track cyclists from the Spanish National Team participated in this study. All them had qualified more than once among the first three finishers in the Spanish National Championship. The group included several National Champions and a silver medalist in the last World Championship, who was a sprint specialist. Five cyclists were sprint specialists, and the other five were endurancetrained cyclists. The mean $\pm \mathrm{SE}$ ages, heights, weights, and percentages of body fat were $19.0 \pm 0.7$ vs. $18.8 \pm 0.4 \mathrm{yr}$, $176 \pm 2$ vs. $179 \pm 0.7 \mathrm{~cm}, 74.7 \pm 3.1$ vs. $65.8 \pm 1.0 \mathrm{~kg}$, and $13.2 \pm 1.9$ vs. $9.3 \pm 0.5 \%$ in the sprint and endurance cyclists, respectively. Subjects were requested to follow similar diets and lessen physical activities during the $48 \mathrm{~h}$ before the experiments. They were also instructed to refrain from any food for at least $4 \mathrm{~h}$ before each test session.

\section{Experimental Protocol and Procedures}

The percentage of body fat was estimated anthropometrically by using a population-specific equation, which was developed and validated in our laboratory by using dual X-ray absorptiometry as a gold standard (19). Subjects completed four test sessions in separate days. First, their maximal $\dot{\mathrm{V}}_{2}\left(\dot{\mathrm{V}}_{2}\right.$ max $)$ and maximal power output (Wmax) were assessed via an incremental exercise test to exhaustion (25 $\mathrm{W} / \mathrm{min}$, at $90 \mathrm{rpm}$ ). During the next 2 testing days, the relationship between $\dot{\mathrm{V}}_{2}$ and intensity (or cycling economy) was determined. Then, during the last test session, Wingate tests were carried out while the subjects were breathing either room air (normoxia) or air from a Douglas bag containing $10.4 \% \mathrm{O}_{2}$ in $\mathrm{N}_{2}$ (hypoxia), equivalent to an altitude of $\sim 5,300 \mathrm{~m}$. This level of acute hypoxia was chosen because it reduces $\dot{\mathrm{V}}_{2}$ max by nearly $50 \%(10,36)$, creating, therefore, a condition in which a potential limitation to aerobic energy supply would be present during the Wingate tests performed in severe hypoxia. Normoxic and hypoxic Wingate tests were performed in random order and separated by a recovery period of at least $1 \mathrm{~h}$, which is enough to allow for a complete recovery (6).

Cycling economy tests. Cycling economy was determined by using 12 submaximal workloads at intensities of between 60 and $90 \% \dot{\mathrm{V}}_{2}$ max , at four different pedaling rates: 60, 80, 100, and $120 \mathrm{rpm}$. Exercise intensities and pedaling rates were administered in random order, separated by rest periods of $3-5 \mathrm{~min}$. To reduce thermal stress and minimize water losses due to sweating, subjects were fan cooled and ingested in total $600 \mathrm{ml}$ of water during the resting periods. Tests were performed at $18-24^{\circ} \mathrm{C}, 60-80 \%$ relative humidity, and 750 $770 \mathrm{mmHg}$ atmospheric pressure. The duration of each submaximal bout was set at 6 min. The mean $\dot{\mathrm{V}}_{2}$ registered during the last 2 min was taken as representative of each submaximal exercise intensity. To relate $\dot{\mathrm{V}}_{2}$ to power, individual nonlinear regression equations were calculated by least-square linear fit, applying the following nonlinear model: $\mathrm{V}_{O_{2}}=a+b \cdot \mathrm{W}+c \cdot \mathrm{rpm}+d \cdot \mathrm{rpm}^{2}$, which gave a standard error of estimate that was always lower than 100 $\mathrm{ml} / \mathrm{min}$ of $\mathrm{O}_{2}$, where $a, b, c$, and $d$ are the constants to be determined by the nonlinear regression equation; $\mathrm{W}$ is the exercise intensity; and rpm is the pedaling rate.

Wingate tests. To determine whole blood lactate concentration ([La]) in the femoral vein, a 20-gauge catheter (Hydrocath, Ohmeda, Swindon, UK) was inserted percutaneously by use of the Seldinger technique into the right femoral vein under local anesthesia (2\% lidocaine) as previously reported (29). The catheter was inserted $2 \mathrm{~cm}$ below the inguinal ligament and was advanced $12 \mathrm{~cm}$ toward the knee to avoid contamination of the blood coming from the deep quadriceps muscle veins with saphenous vein blood. Once in place, the catheter was sutured to the skin to minimize the risk of movement or creasing, and the outlet of the catheter was connected to a three-way stopcock. After a resting period of $\sim 5$ min, subjects carried out a standardized warm-up consisting of $10 \mathrm{~min}$ of continuous cycling at an intensity close to $60 \% \dot{\mathrm{V}}_{2}$ max followed by five maximal accelerations lasting for no more than 5-6 s. Then the subjects rested for $10 \mathrm{~min}$ and were randomly assigned to a normoxic or hyperoxic Wingate test. To minimize the risk of hypotension and respiratory alkalosis during the hypoxic Wingate tests, the subjects commenced to breathe from the hypoxic gas bag only 3 min before the onset of the exercise (36). During the Wingate tests, femoral vein blood samples were drawn continuously for periods of $5 \mathrm{~s}$, given a total of six exercise samples. An hour later, the Wingate test was repeated in the other condition. After both Wingate tests, the subjects recovered in normoxia while lying on a bed, and additional blood samples were withdrawn from the femoral vein $3,5,7$, and $10 \mathrm{~min}$ after the start of the recovery period. Braking forces equivalent to $0.11 \mathrm{kp}$ per $\mathrm{kg}$ of body mass were used in all cyclists.

All cycling tests were carried out on a Monark cycle ergometer (Monark 818E). During the Wingate tests double-toe stirrups and straps were used to tightly fix the feet to the pedals. To record the pedal velocity every $2 \mathrm{~ms}$, a disk with 250 slots was connected through a gear to the chain (6). The slotted disk was turning in front of a photoelectric cell interfaced with a computer. The work performed on the Monark cycle ergometer was corrected for the work required to accelerate the flywheel, as reported elsewhere (6). Briefly, the load on the cycle ergometer was considered as the sum of the frictional load (braking force applied through the belt to the flywheel) and the load that would be required at any instant to stop the subject from accelerating the flywheel, which depends on the flywheel's moment of inertia and other frictional forces acting on the flywheel. To calculate this load, we generated a series of deceleration curves using different frictional loads. First, the flywheel was set in motion at a constant speed of $120 \mathrm{rpm}$ by pedaling. Second, after achieving a steady speed, pedaling was suddenly interrupted and the time elapsed between 105 and 0 rpm was used to calculate the deceleration for each braking force. Lastly, a regres- 
sion equation was derived by least-square linear fit between flywheel deceleration and load.

The anaerobic energy yield during the Wingate tests was calculated as the $\mathrm{O}_{2}$ deficit as previously reported (6). First, the $\mathrm{O}_{2}$ demand was estimated individually by extrapolating the nonlinear relationship between $\dot{\mathrm{V}}_{2}$ and power output measured at submaximal loads. Then the $\mathrm{O}_{2}$ deficit was computed as the difference between the $\mathrm{O}_{2}$ demand and the $\mathrm{O}_{2}$ consumed during the supramaximal bouts $(25,39)$.

Respiratory variables. Ventilatory and gas exchange variables were monitored breath-by-breath by an open-circuit sampling system (CPX, Medical Graphics, St. Paul, MN) and averaged every $15 \mathrm{~s}$ during the incremental exercise tests and every $5 \mathrm{~s}$ during the Wingate tests. The metabolic cart was calibrated with calibration gas mixtures of known $\mathrm{O}_{2}$ and $\mathrm{CO}_{2}$ concentrations (accuracy $0.01 \%$ ), which were provided by the manufacturer (CPX, Medical Graphics). In our laboratory, $\dot{\mathrm{V}}_{2}$ and $\mathrm{CO}_{2}$ production during submaximal cycling has been assessed with a coefficient of variation lower than $5 \%$, as well as with an intraclass reliability coefficient higher than 0.98, as determined in six physical education students at four different intensities on 4 different days. The highest $\dot{\mathrm{V}}_{2}$ value attained during the incremental exercise tests was taken as the $\dot{\mathrm{V}}_{2}$ max, whereas the intensity attained just before exhaustion is referred to as Wmax. The Wmax was adjusted by extrapolation depending on the duration of the last step (18). To determine the kinetics of the $\dot{\mathrm{V}}_{2}$ on-response, breath-by-breath data were averaged every $5 \mathrm{~s}$ and fit to a curve by using an exponential model, by means of the least-squares error approach. The curve-fitting procedure was iterated until any further changes in the parameters for the model did not result in a reduction in the mean squared error between the curve obtain from the model and the original data set. The model used to fit the $\dot{\mathrm{V}}_{2}$ on-data had a constant, which corresponds to resting $\dot{\mathrm{V}}_{2}$, an amplitude term $(b)$, and a time constant $(c)$ as follows

$$
\dot{\mathrm{V}}_{2}(t)=a+b\left(1-e^{-c t}\right)
$$

where $t$ is the time in seconds and $\dot{\mathrm{V}}_{2}(t)$ is the time-dependent variation in $\dot{\mathrm{V}}_{2}$.

Blood lactate. [La] was determined in whole blood by using a lactate analyzer (YSI 1500 Sport, Yellow Springs, CO) provided with hemolyzing agent (Triton X-100). With this instrument, we obtained a coefficient of variation for whole blood [La] assessment lower than 1\%, for [La] between 1 and $26 \mathrm{mM}$. Recovery blood [La] curves were integrated over time and expressed as millimolar $\cdot$ seconds. Reported values correspond to the net area under curve, i.e., the area under the curve after accounting for the resting blood [La] immediately before the start of the Wingate tests.

\section{Statistical Analysis}

Descriptive statistics were performed on each variable to confirm the assumptions of normality and homocedasticity. The effect of $\mathrm{O}_{2}$ inspired fraction on femoral blood lactate during the Wingate tests was determined using a two-way repeated-measures analysis of variance with cyclists specialty as a two-level factor. In the case of a significant $F$ value, planned comparisons were carried out by using a Student's paired or unpaired (as appropriate) $t$-test with Bonferroni correction to account for multiple comparisons. The significance level was set at $P<0.05$. Data are expressed as means $\pm \mathrm{SE}$.

\section{RESULTS}

\section{Differences Between Endurance- and Sprint-Trained Cyclists}

Endurance cyclists showed higher $\dot{\mathrm{V}}_{2}$ max than the sprint-trained cyclists $\left(72 \pm 1\right.$ and $62 \pm 2 \mathrm{ml} \cdot \mathrm{kg}^{-1}$. $\left.\min ^{-1}, P<0.05\right)$. As depicted in Fig. $1 A$ and Table 1 , absolute and relative peak power output (Pmax) and Pmean were greater in the sprint than in the endurance cyclists. Accordingly, sprint cyclists reached greater maximal and mean pedaling rates than endurance-trained cyclists (Fig. 1B). Sprint cyclists, however, fatigued faster than the endurance cyclists, as indicated by the fatigue index during the Wingate test, which was $0.46 \pm 0.12$ and $0.32 \pm 0.12 \mathrm{~W} \cdot \mathrm{s}^{-1} \cdot \mathrm{kg}^{-1}$ body mass in the sprint and endurance cyclists, respectively (Fig. 2A; $P<0.05$ ). In consequence, the sprint cyclists' superiority in power output was reduced progressively during the second half of the Wingate tests, developing in both groups almost similar power output values per kilogram of body mass during the last $15 \mathrm{~s}$ (Fig. 1A). The sprint cyclists incurred a greater $\mathrm{O}_{2}$ demand during the first 10-15 s of the Wingate test (Fig. 1, C and D). Likely because of their greater $\dot{\mathrm{V}}_{2}$ max, the endurance cyclists were able to consume $26 \%$ more $\mathrm{O}_{2}$ per kilogram of body mass during the Wingate tests than the sprint cyclists $(P<0.05)$, because both groups utilized a similar percentage of their $\dot{\mathrm{V}}_{2}$ max during the Wingate tests in normoxia (Fig. $2 B$ ). In fact, a close correlation was observed between the mean $\dot{\mathrm{V}}_{2}$ during the Wingate test and $\dot{\mathrm{V}}_{2}$ max (Fig. $2 C ; r=0.86, P<0.001)$. With greater $\mathrm{O}_{2}$ demand and lower $\dot{\mathrm{V}}_{2}, \mathrm{O}_{2}$ deficit per kilogram of body mass resulted $33 \%$ higher in the sprint than the endurance cyclists (Fig. 1H). The difference between $26 \%$ superior aerobic energy yield in the endurance cyclists and 33\% greater $\mathrm{O}_{2}$ deficit in the sprint cyclists leads to the $\sim 8 \%$ superior Pmean developed during the Wingate by the sprint specialists. Despite these remarkable differences in anaerobic energy yield during the Wingate tests, the rate of femoral vein blood [La] accumulation during exercise was similar in the endurance and sprint cyclists. In both groups, femoral blood [La] did not change during the first $15 \mathrm{~s}$ of exercise, but thereafter it augmented, describing a parabola as exercise time passed (in all conditions, $r=0.99, P<0.001$; Fig. $1 G)$. During the first $10 \mathrm{~min}$ of the recovery period, the sprint cyclists accumulated $27 \%$ more lactate in the femoral vein than their endurance counterparts $(P<$ 0.05; Fig. 3).

As depicted in Fig. 4 the anaerobic energy contribution to the overall energy expended during the Wingate test decreased following a parabolic pattern $(r>0.98$, $P<0.01)$. The sprint cyclists obtained a slightly greater proportion of energy through the anaerobic pathways (Table 1). Extrapolation of the curves depicted in Fig. 3 to $0 \%$ anaerobic energy contribution permits us to predict the duration that an all-out test should have to enable a complete utilization of all the 

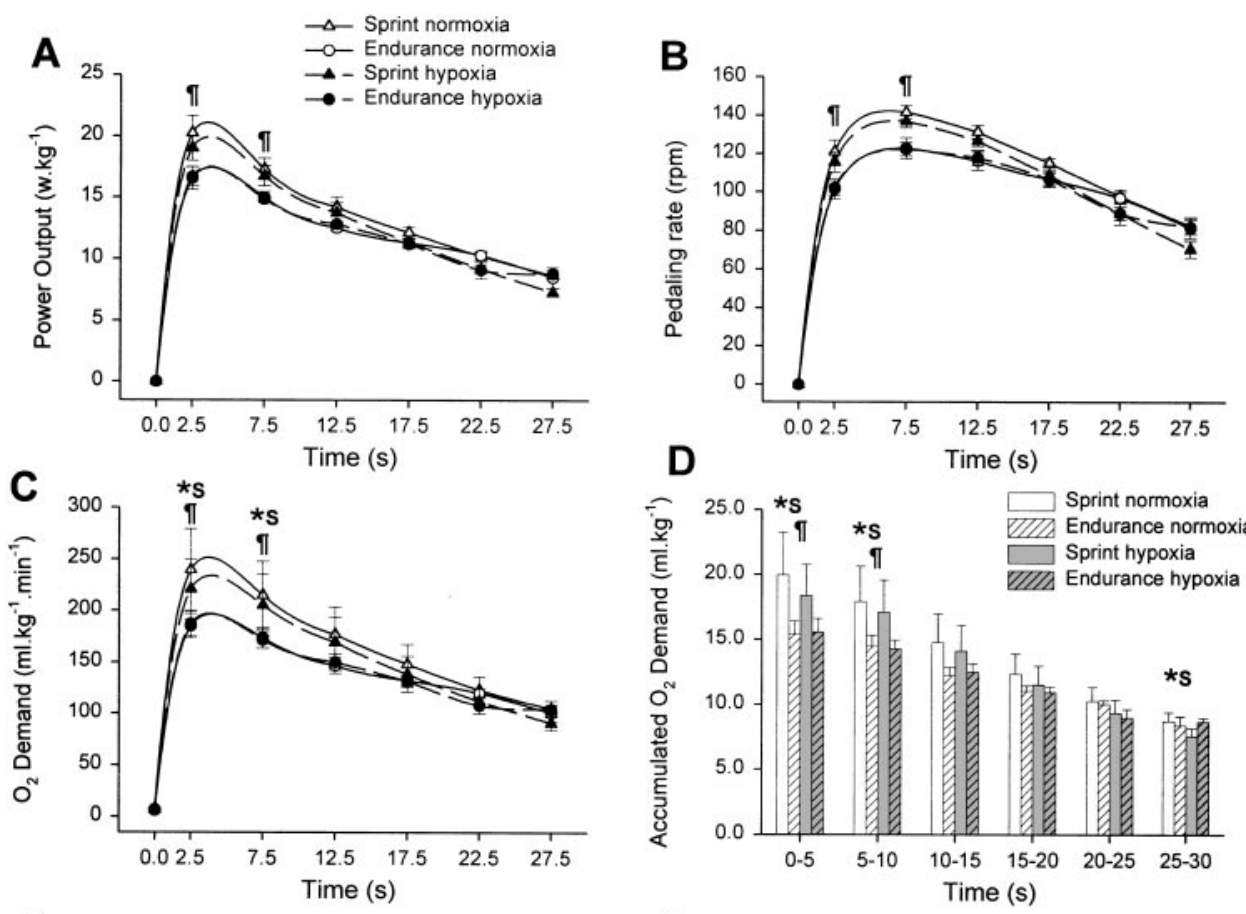

Fig. 1. Time course of power output $(A)$, pedaling rate $(B), \mathrm{O}_{2}$ demand $(C)$, accumulated $\mathrm{O}_{2}$ demand $(D), \mathrm{O}_{2}$ uptake $\left(\dot{\mathrm{V}}_{2} ; E\right)$, accumulated $\dot{\mathrm{V}}_{2}(F)$, femoral blood lactate concentration $(G)$, and $\mathrm{O}_{2}$ deficit $(H)$ during 30 -s Wingate tests in normoxia and acute severe hypoxia. ${ }^{*} P<0.05$ normoxia vs.

E
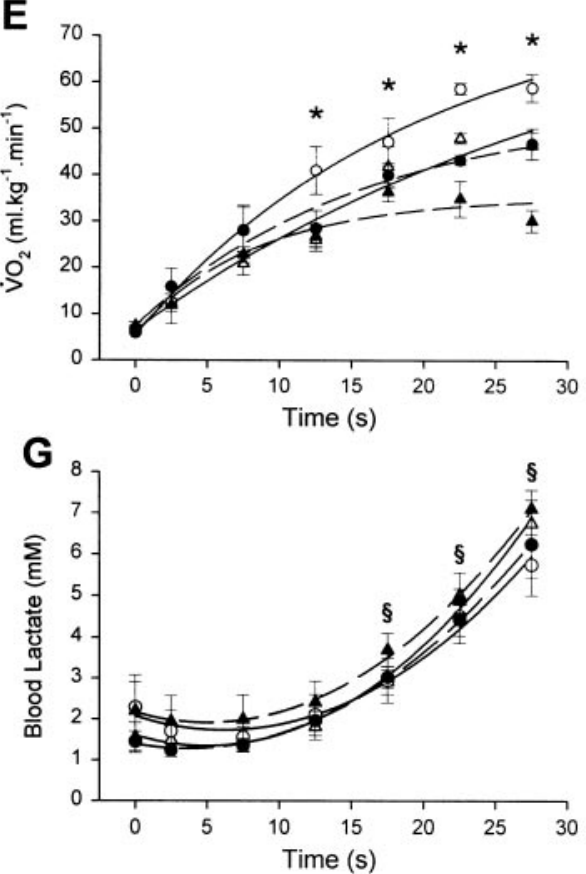

$\mathbf{F}$
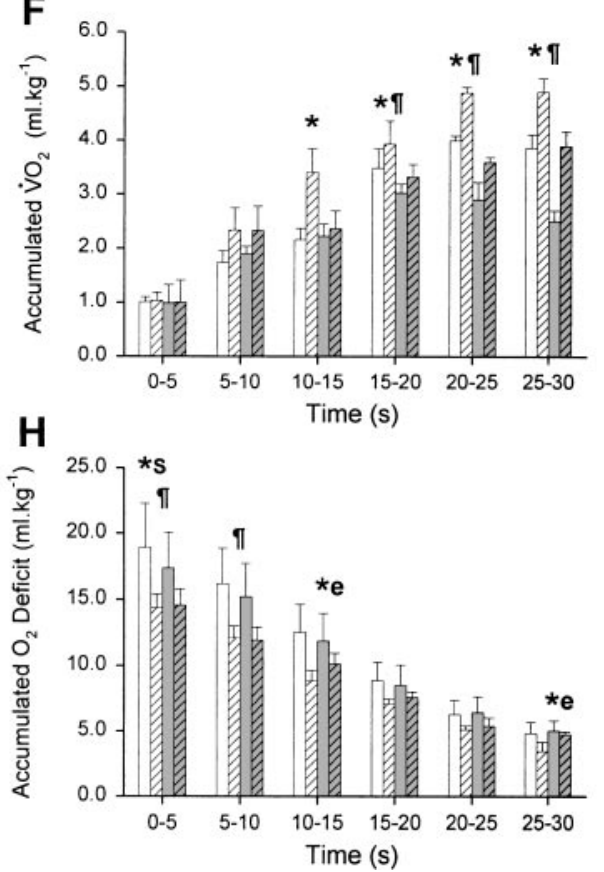
hypoxia; II $P<0.05$ sprint vs. endurance-trained cyclists; $\S P<0.05$ compared with time $0 ; * \mathbf{S} P<0.05$ normoxia vs. hypoxia, but only for the sprint cyclists; $* \mathbf{e} P<0.05$ normoxia vs. hypoxia, but only for the endurance cyclists. anaerobic energy potential (Fig. 4). Because the sprint cyclists had larger $\mathrm{O}_{2}$ deficit and obtained a greater fraction of energy through the anaerobic pathways, the rate of anaerobic energy release was much higher in the sprint than in the endurance cyclists. Despite this fast recruitment of their anaerobic capacity, the sprint cyclists needed $4-5 \mathrm{~s}$ more than the endurance cyclists to fully express their anaerobic capacity.

\section{Effect of Severe Acute Hypoxia}

The time course of power output, $\mathrm{O}_{2}$ demand, $\dot{\mathrm{V}}_{2}, \mathrm{O}_{2}$ deficit, and blood [La] during the normoxic and hypoxic
Wingate tests are depicted in Fig. 1. Although Pmax was not affected by hypoxia in any group, Pmean and pedaling rate were reduced by $6-7 \%$ in the sprint cyclists $(P<0.05)$. In the endurance cyclists, however, Pmean and pedaling rate remained at same level as in normoxia. With a lower Pmean, $\mathrm{O}_{2}$ demand was diminished in the sprint cyclists exercising in hypoxia $(P<$ $0.05)$. In both groups, hypoxia resulted in a $16 \%$ lower mean $\dot{\mathrm{V}}_{2}(P<0.01$; Fig. $1 E)$. The divergence between normoxic and hypoxic $\mathrm{V}_{2}$ during the Wingate test began $10 \mathrm{~s}$ after the start of the test and became more accentuated as the exercise progressed $(P<0.05)$. 
Table 1. Differences between sprint- and endurance-trained cyclists

\begin{tabular}{|c|c|c|c|c|}
\hline & \multicolumn{2}{|c|}{ Normoxia } & \multicolumn{2}{|c|}{ Hypoxia } \\
\hline Pmax & $1,547 \pm 128$ & $1,122 \pm 65 \dagger$ & $1,490 \pm 153$ & $1,128 \pm 54 \dagger$ \\
\hline RPMmax, rpm & $156.5 \pm 3.4$ & $134.3 \pm 5.7 \dagger$ & $153.3 \pm 4.5$ & $134.0 \pm 3.9 \dagger$ \\
\hline TRPMmax, s & $5.89 \pm 0.36$ & $6.57 \pm 0.53$ & $6.41 \pm 0.49$ & $6.76 \pm 0.20$ \\
\hline Pmean, W & $1,030 \pm 52$ & $813 \pm 22 \dagger$ & $962 \pm 51^{*}$ & $805 \pm 20 \dagger$ \\
\hline Pmean, W/kg & $13.8 \pm 0.6$ & $12.4 \pm 0.3 \dagger$ & $12.9 \pm 0.6^{*}$ & $12.2 \pm 0.2 \dagger$ \\
\hline$\dot{\mathrm{V}} \mathrm{O}_{2}, \mathrm{ml}$ & $1,207 \pm 31$ & $1,350 \pm 78$ & $1,010 \pm 87$ & $1,127 \pm 60$ \\
\hline $\mathrm{V}_{2}, \mathrm{ml} / \mathrm{kg}$ & $16.3 \pm 0.8$ & $20.5 \pm 1.1 \dagger$ & $13.6 \pm 1.2^{*}$ & $17.2 \pm 1.0^{* \dagger}$ \\
\hline $\mathrm{O}_{2} \mathrm{D}, \mathrm{ml}$ & $5,011 \pm 811$ & $3,365 \pm 219 \dagger$ & $4,770 \pm 761^{*}$ & $3,591 \pm 269 \dagger$ \\
\hline $\mathrm{O}_{2} \mathrm{D}, \mathrm{ml} / \mathrm{kg}$ & $67.7 \pm 11.4$ & $51.0 \pm 2.6 \dagger$ & $64.4 \pm 10.7^{*}$ & $54.4 \pm 3.3 \dagger$ \\
\hline Anaerobic, \% & $79.3 \pm 2.7$ & $71.2 \pm 1.6 \dagger$ & $81.0 \pm 3.4$ & $76.5 \pm 1.8$ \\
\hline [La], mM & $3.2 \pm 0.3$ & $3.1 \pm 0.5$ & $3.7 \pm 0.3$ & $3.0 \pm 0.3$ \\
\hline
\end{tabular}

Values are means \pm SE. Pmax, peak pace; RPMmax, maximal pedaling rate; TRPMmax, time for pedaling rate to peak; Pmean, mean power output; RPMmean, mean pedaling rate; $\mathrm{O}_{2} \mathrm{Dem}, \mathrm{O}_{2}$ demand; $\dot{\mathrm{V}}_{2}, \mathrm{O}_{2}$ uptake; $\mathrm{O}_{2} \mathrm{D}, \mathrm{O}_{2}$ deficit; Anaerobic, percentage of energy yield provided by the anaerobic metabolism; [La], blood lactate concentration in the femoral vein. * Significant difference from normoxia to hypoxia; $\dagger$ significant difference between sprint- and endurance-trained cyclists.

Hypoxia had opposed effects on $\mathrm{O}_{2}$ deficit in sprint and endurance cyclists, inasmuch as, compared with normoxia, hypoxia resulted in a $5 \%$ lower $\mathrm{O}_{2}$ deficit in the sprint cyclists $(P<0.05)$, whereas it promoted a $7 \%$ greater value in the endurance cyclists $(P<0.05)$. This different effect was further sustained by a significant interaction effect in the ANOVA analysis. In agreement, the endurance cyclists achieved an $11 \%$ greater area under the blood [La] curve during the recovery period after the hypoxic Wingate tests $(P<0.05$; Fig. 3 , whereas recovery [La] was unaffected by hypoxia in the sprint cyclists. During the 30 -s exercise period, however, the rate of blood lactate accumulation was similar in normoxia and hypoxia (Fig. 1G). Fatigue index was also similar in normoxia and hypoxia (Fig. $2 A)$. The anaerobic contribution to the energy expenditure in hypoxia was greater than in normoxia. However, this effect was significant only in the endurance cyclists $(P<0.05)$.

\section{DISCUSSION}

The effect of severe acute hypoxia, equivalent to an altitude of $\sim 5,300 \mathrm{~m}$, on exercise metabolism and performance has been studied in elite endurance and sprint-trained track cyclists. This study demonstrates that severe acute hypoxia does not alter peak power output and fatigue index during 30 -s Wingate test. In contrast, Pmean is reduced with acute severe hypoxia in sprint but not in endurance-trained cyclists, despite the fact that in both groups mean $\dot{\mathrm{V}}_{2}$ was reduced by 16\% during the Wingate tests in hypoxia. In addition, it has been shown that, compared with sprint, endurance-trained cyclists display superior maximal aerobic power, attain lower Ppeak and Pmean, achieve a lower $\mathrm{O}_{2}$ deficit, have a lower fatigue index, obtain a greater fraction of the energy expended via oxidative pathways during a 30-s Wingate test, and show a lower femoral venous blood [La] after the Wingate test.

\section{Effect of Severe Acute Hypoxia}

In contrast to our hypothesis, Wingate test performance was only reduced with severe acute hypoxia in the elite sprint cyclists whereas it was maintained in the endurance cyclists. In both groups, $\mathrm{V}_{\mathrm{O}_{2}}$ was lowered in the same proportion (i.e., $16 \%$ ), but because $\dot{\mathrm{V}}_{2}$ per kilogram of body mass was larger in the endurance cyclists, the absolute reduction of $\dot{\mathrm{V}}_{2}$ was slightly greater in the endurance than the sprint cyclists. If we assume similar cycling efficiencies in normoxia and acute hypoxia, the only possible explanation for these findings is superior anaerobic energy release in hypoxia (39). The fact that $\mathrm{O}_{2}$ deficit increased with hypoxia in the endurance but not in the sprint cyclists supports this concept. Several metabolic pathways are stimulated to supplement energy production when aerobic metabolism is not capable of matching aerobic ATP production to consumption, especially the splitting of phosphocreatine and glycolysis. To our knowledge only McLellan et al. (23) have investigated the effect of moderate acute hypoxia on muscle metabolism during the Wingate test. They reported that, compared with normoxia, muscle [La] doubles when Wingate tests are performed in acute hypoxia. Because the glycolytic branch of the anaerobic metabolism represents $\sim 3 / 4$ of the anaerobic capacity $(1,3,33)$, an increase in muscle lactate accumulation of the magnitude reported by McLellan et al. (23) would account for most of the reduction in aerobic ATP generation with hypoxia in the present study.

It has been shown that during all-out bicycling lactate production commences almost at the onset of muscular contractions reaching concentrations up to $\sim 7$ (11), $\sim 11$ (16), and $\sim 17-29 \mathrm{mM}(3,16,23,28)$ in 6,10 , and $30 \mathrm{~s}$, respectively. Despite the superior muscle lactate accumulation with hypoxia, recovery blood [La] (measured in a forearm vein) was found to be slightly lower in hypoxia in one study (23) and similar to the 

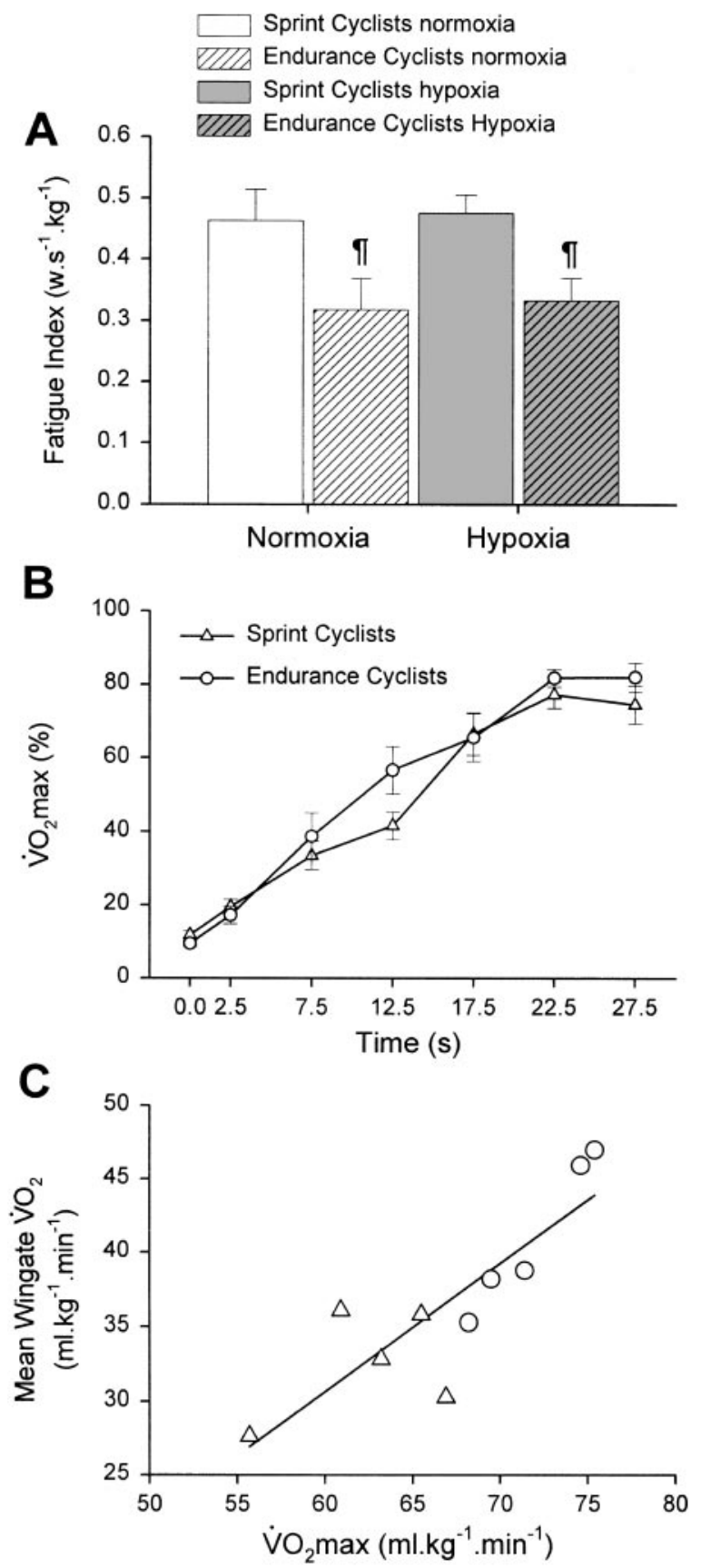

Fig. 2. A: fatigue index during 30 -s Wingate tests. $B$ : percentage of utilization of maximal $\dot{\mathrm{VO}}_{2}\left(\mathrm{~V}_{2}\right.$ max $)$ during the Wingate tests performed in normoxia. $C$ : relationship between mean $\mathrm{V}_{2}$ during the Wingate test in normoxia and $\mathrm{VO}_{2 \text { max }}$. $I P<0.05$ sprint vs. endurance-trained cyclists.

normoxic conditions in another study from the same group (22). In a novel procedure, in the present study blood was sampled from the vicinity of the contracting muscle because systemic and local arm metabolism may interfere with forearm [La]. Moreover, by sampling blood every $5 \mathrm{~s}$ we have been able to measure for the first time the kinetics of femoral vein blood [La] accumulation during Wingate tests. Our data demonstrate that the kinetics of femoral venous blood lactate accumulation is independent of $\mathrm{F}_{\mathrm{I}_{2}}$ during 30 -s all-out exercise. In both conditions there was a 15 -s lag between the onset of exercise and the beginning of blood lactate accumulation, indicating that most of the lactate produced at the onset of exercise is retained inside the muscle. No clue is given by the present study to explain why lactate is not released during the first $15 \mathrm{~s}$ of exercise. If the principal motor driving lactate net
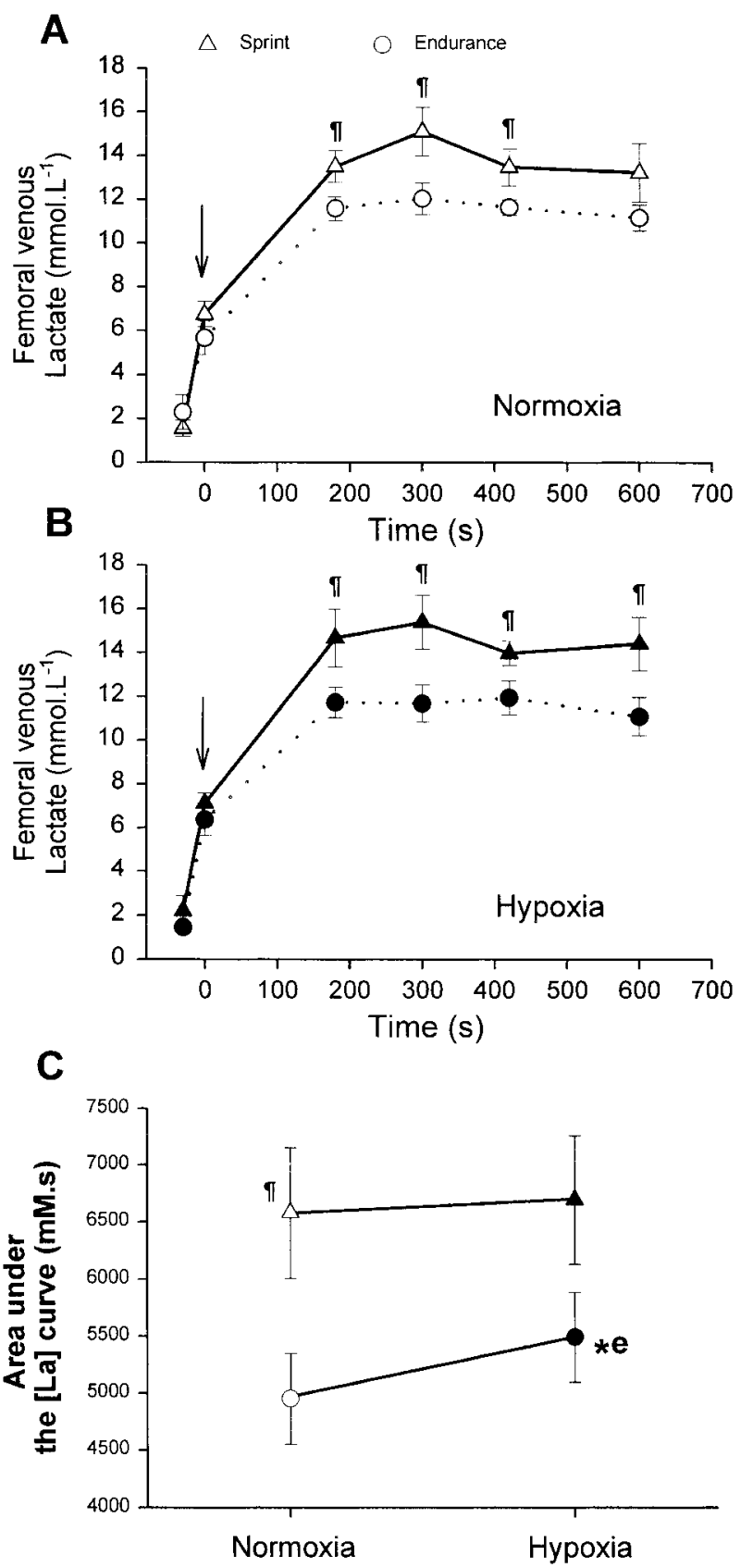

Fig. 3. A: recovery of femoral blood lactate concentrations ([La]) after the Wingate test in normoxia. $B$ : recovery of femoral blood lactate concentrations after the Wingate test in hypoxia. $C$ : area under the curve of blood [La] in the femoral vein during the first 10 min of the recovery period (basal values discounted). II $P<0.05$ sprint- vs. endurance-trained cyclists. $* \mathbf{e} P<0.05$ normoxia vs. hypoxia, but only for the endurance cyclists. The vertical arrow indicates the time point corresponding to the end of the Wingate test (time 0 of the recovery curve). 


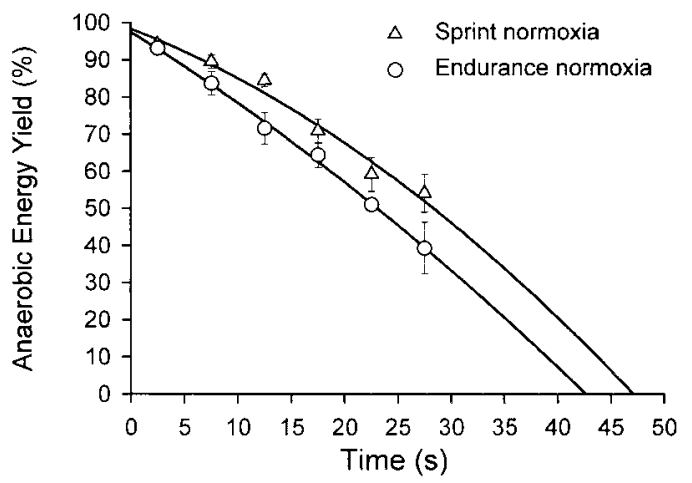

Fig. 4. Fraction of energy provided by anaerobic sources during 30-s Wingate tests performed in normoxia. A parabola was fitted to each set of data points $(r=0.99, P<0.01)$ and extrapolated to $0 \%$ anaerobic contribution to estimate the time required to utilize the totality of the anaerobic capacity during an all-out test performed in normoxia.

release is muscle $\mathrm{pH}(30)$, the fact that muscle $\mathrm{pH}$ is barely changed at the onset of exercise could facilitate muscle lactate accumulation, or perhaps the muscle lactate transporters must first be activated.

A number of studies have shown that the total anaerobic capacity cannot be used up in $30 \mathrm{~s}(6,7,25,26$, $31,33,35)$. Hypoxia appears to stimulate additional utilization of the anaerobic capacity to compensate for the reduction in aerobic ATP production. This effect was clear in the endurance cyclists, whereas the sprint cyclists showed a small reduction in their $\mathrm{O}_{2}$ deficit, which, combined with the lower $\dot{\mathrm{V}}_{\mathrm{O}_{2}}$, led to decreased Pmean. The critical question is what limits performance during the Wingate test? Our findings contrast with the prevailing paradigm, which proposes that performance during the Wingate test is limited by the rate of anaerobic energy release $(2,7)$, which, in turn, depends on substrate availability and enzymatic control $(7,28,35)$. It is well known that performance during the Wingate test is not limited by glycogen availability $(16,17,23,26)$. Our study novelly shows that neither the availability of anaerobic energy nor the rate of anaerobic energy release limits performance during the Wingate test in the elite endurance cyclists. Our results point to the rate of ATP utilization as the performance-limiting factor during the traditional Wingate test. According to our results, the factors reducing the rate of ATP hydrolysis should be common to the aerobic and anaerobic pathways. This requirement is fulfilled by ADP and $\mathrm{P}_{\mathrm{i}}$, which accumulate during all-out exercise and thus could set the upper limit of ATP utilization throughout their inhibitory effects on muscle contraction $(9,38)$. In contrast, according to our results, performance in sprint cyclists appears to be substrate limited in hypoxia, as reported in normoxia in nontrained (35) and physically active subjects (7).

It should be highlighted that the level of hypoxia used in our study is very close to the limit that a human can tolerate acutely. During incremental exercise to exhaustion under these conditions, arterial $\mathrm{Po}_{2}$ values at exhaustion approached $30-35 \mathrm{mmHg}$ (36). This level of hypoxia is very close to the limit that can be tolerated for a short time by an unacclimatized human and is similar to that reported in altitudeacclimatized subjects at the summit of Mt. Everest simulated in Operation Everest II (34). Severe hypoxemia, in turn, could have elicited central fatigue (27) or reduced peak leg blood flow (5). Although we cannot rule out a central component in fatigue appearance, in agreement with previous investigations performed with lower levels of hypoxia $(22,23)$, no effect of severe acute hypoxia on fatigue index or peak power output was found in this study. Furthermore, clinical signs of fatigue and the ventilatory response during the hypoxic Wingate tests (data not shown) were similar in both groups of cyclists. It does not seem, therefore, that differences in central fatigue mechanisms could explain the reduction of performance with hypoxia in the sprint cyclists.

Oxygen deficit, as measured in this study, is not a pure estimation of the anaerobic energy utilized because the $\mathrm{O}_{2}$ consumed from the $\mathrm{O}_{2}$ stores [especially $\mathrm{O}_{2}$ bound to myoglobin, which has been estimated to be $2 \mathrm{mmol} / \mathrm{kg}$ wet wt (14), and $\mathrm{O}_{2}$ bound to hemoglobin] at the onset of the exercise is computed as the $\mathrm{O}_{2}$ deficit, leading to an overestimation of the anaerobic energy production and, conversely, an underestimation of the real $\dot{\mathrm{V}}_{2}$ (25). This intrinsic error of the deficit method is, however, rather small because of the comparatively low amount of $\mathrm{O}_{2}$ stored in the skeletal muscle in relation to the magnitude of the $\mathrm{O}_{2}$ deficit. If exercise bouts are performed in normoxia and hypoxia, the $\mathrm{O}_{2}$ stores at the beginning of the exercise would be lower in the hypoxic condition, reducing the overestimation of the $\mathrm{O}_{2}$ deficit. Resting myoglobin saturation, however, was likely very similar in normoxia and hypoxia, owing to the especial characteristics the $\mathrm{O}_{2}$ dissociation myoglobin curve, which has an $\mathrm{O}_{2}$ pressure at which myoglobin saturation is $50 \%$ that is close to 3 $\mathrm{mmHg}$ (30). With the level of hypoxia used in this study, a resting arterial $\mathrm{PO}_{2}$ of $45-50 \mathrm{mmHg}$ and saturation of $\sim 80 \%$ have been reported (32). Consequently, the amount of $\mathrm{O}_{2}$ stored as $\mathrm{O}_{2}$ bound to hemoglobin was probably $20 \%$ lower at the onset of the hypoxic Wingate test. If this was actually the case, the hypoxia-normoxia $\mathrm{O}_{2}$ deficit difference could have been even higher than the $7 \%$ calculated for the endurance cyclists, and perhaps no reduction in $\mathrm{O}_{2}$ deficit with hypoxia would have been observed in the sprint cyclists. Assuming that both groups had a similar reduction in their $\mathrm{O}_{2}$ stores with hypoxia, our data demonstrate that endurance cyclists have a greater capacity to enhance the anaerobic energy production in response to hypoxia than the sprint cyclists. Perhaps the sprint cyclists are already using their anaerobic energy at a rate close to the maximum in normoxia, and, thus, they are not be able to compensate for a reduction in aerobic ATP production with hypoxia via an enhancement of rate of anaerobic energy release. 


\section{Differences Between Endurance and Sprint Specialists}

One singularity of this study is the outstanding level of the cyclists examined, who were among the best in Spain with several very successful achievements in international competitions in both groups. In the case of the sprint cyclists, Ppeak and Pmean were among the highest reported in literature $(8,12,22,23,40)$. It should be mentioned that the Pmax obtained in the Monark cycle ergometer was similar to and closely correlated with the Pmean measured during the first $30 \mathrm{~s}$ of a $500 \mathrm{~m}$ track sprint (measured in the 10 cyclists here studied with a SRM ergometer, data not shown; Ref. 8). The Pmean developed by these cyclists was far beyond the maximal aerobic power output; accordingly, $\mathrm{O}_{2}$ deficit was also higher than reported in previous studies for cyclists $(8,13,40)$. As expected, sprint cyclists had lower $\mathrm{V}_{2}$ max but much larger $\mathrm{O}_{2}$ deficit than the endurance specialists $(8,24)$. Assuming that the sprint cyclists utilized $80-90 \%$ of their anaerobic capacity in $30 \mathrm{~s}(6,25,31,33)$, their actual maximal accumulated $\mathrm{O}_{2}$ deficit can be estimated to lie in between 75 and $85 \mathrm{ml} / \mathrm{kg}$. In fact, it has been suggested that world class sprint athletes may reach even higher $\mathrm{O}_{2}$ deficits $(8,25,31)$. The superiority of sprint cyclists in anaerobic power and capacity is probably the result of an increased percentage of type II fibers, more appropriate enzymatic machinery to produce ATP through anaerobic pathways, and enhanced buffer capacity $(8,13,20,21)$. However, fatigue index was markedly higher in the sprint than the endurance cyclists. Because sprint cyclists have a higher proportion of type II fibers than the endurance cyclists (21), they should choose a faster pedaling rate, because type II fibers are more efficient at a faster contraction speed (15). The drawback of this strategy is that type II fibers are less resistant to fatigue (15). The election of high pedaling frequencies may be advantageous for speed in track competitions (37). In an interesting experiment using an isokinetic cycle ergometer, Jones et al. (17) demonstrated that the same Pmean is developed at 60 and $140 \mathrm{rpm}$, but peak power output is considerably higher at $140 \mathrm{rpm}$, at the price, however, of an increased fatigue index.

Withers et al. (40) reported that endurance-trained cyclists can utilize $94 \%$ of their anaerobic capacity in a 45-s all-out test. Using a different approach, we have estimated that the endurance cyclists might utilize the totality of their anaerobic capacity in $43 \mathrm{~s}$ whereas the sprint cyclists would need $47 \mathrm{~s}$ (see Fig. 3).

\section{Limitations of the $\mathrm{O}_{2}$ Deficit as a Measure of the Anaerobic Energy Yield}

Despite the limitations of $\mathrm{O}_{2}$ deficit as a method to estimate the anaerobic energy yield, we should emphasize that our estimations on the partitioning between aerobic and anaerobic energy sources during the Wingate test agree amazingly well with the ATP turnover rates reported by Parolin et al. (28). These authors measured the aerobic and anaerobic ATP turnover rate in muscle biopsies obtained at three different time points during an isokinetic Wingate test at $100 \mathrm{rpm}$. During the last $15 \mathrm{~s}$ of the Wingate test, the mean aerobic contribution to the energy expenditure was $54 \%$ in Parolin et al.'s work and $48 \%$ in our endurance cyclists. The small difference between our estimations and the biopsy data of Parolin et al. probably reflects the fact that lactate release from the muscle was not accounted for in Parolin et al.'s work. Thus they probably underestimated slightly the anaerobic contribution during the last $15 \mathrm{~s}$ of the Wingate test, a period in which we have shown an increase in femoral venous lactate.

The real values of $\mathrm{O}_{2}$ deficit could be lower or higher than reported here, but if we assume that mechanical efficiency during the Wingate tests was similar in normoxia and acute hypoxia, as has been demonstrated for submaximal exercise, then our conclusion that anaerobic energy production is increased during 30 -s all-out exercise in hypoxia to account for the reduction in $\dot{\mathrm{V}}_{2}$ is irrefutable.

In summary, the effects of severe acute hypoxia, equivalent to an altitude of $\sim 5,300 \mathrm{~m}$, on exercise metabolism and performance have been studied in elite endurance- and sprint-trained track cyclists. We have demonstrated that peak power output and fatigue index are not altered by severe acute hypoxia, whereas mean $\dot{\mathrm{V}}_{2}$ is reduced by $16 \%$ in endurance- and sprinttrained cyclists. Interestingly, despite this marked reduction in $\dot{\mathrm{V}}_{2}$, only endurance-trained cyclists are able to maintain Pmean by increasing their anaerobic energy production, which shows that neither anaerobic capacity nor the rate of anaerobic energy release limits Wingate test performance in endurance cyclists. Conversely, a small decrease, inferior to that expected from the reduction in $\mathrm{V}_{2}$, of Pmean with hypoxia is observed in the sprint-trained cyclists. Endurancetrained cyclists, on the other hand, possess superior maximal aerobic power and obtain a greater fraction of the energy expended during a Wingate test via oxidative pathways than sprint-trained cyclists. In turn, sprint-trained cyclists display larger $\mathrm{O}_{2}$ deficit $(+33 \%)$, rely more on anaerobic energy sources, and achieve higher peak and Pmean during a Wingate tests. Sprint-trained cyclists, however, develop fatigue at a faster rate than endurance-trained cyclists during supramaximal all-out exercise. In contrast to the prevailing paradigm, this study shows for the first time that performance during the traditional Wingate test is not limited by anaerobic energy supply in endurance cyclists.

We would like to thank Jose Navarro de Tuero, Angel Vivas, and Mecánico Mei for excellent technical assistance.

This study was supported by a grant (08/UNI01/99) from Centro de Alto Rendimiento y de Investigación en Ciencias del Deporte, Consejo Superior de Deportes de España and by the University of Las Palmas de Gran Canaria (Proyectos de Infraestructura 2000).

\section{REFERENCES}

1. Bangsbo J, Gollnick PD, Graham TE, Juel C, Kiens B, Mizuno M, and Saltin B. Anaerobic energy production and $\mathrm{O}_{2}$ 
deficit-debt relationship during exhaustive exercise in humans. J Physiol 422: 539-559, 1990.

2. Bar-Or O. The Wingate anaerobic test. An update on methodology, reliability and validity. Sports Med 4: 381-394, 1987.

3. Bogdanis GC, Nevill ME, Boobis LH, Lakomy HK, and Nevill AM. Recovery of power output and muscle metabolites following $30 \mathrm{~s}$ of maximal sprint cycling in man. $J$ Physiol 482: 467-480, 1995.

4. Boushel R, Calbet JA, Radegran G, Sondergaard H, Wagner PD, and Saltin B. Parasympathetic neural activity accounts for the lowering of exercise heart rate at high altitude. Circulation 104: 1785-1791, 2001.

5. Calbet JA. Oxygen tension and content in the regulation of limb blood flow. Acta Physiol Scand 168: 465-472, 2000.

6. Calbet JA, Chavarren J, and Dorado C. Fractional use of anaerobic capacity during a 30 - and a 45 -s Wingate test. Eur J Appl Physiol 76: 308-313, 1997.

7. Casey A, Constantin-Teodosiu D, Howell S, Hultman E, and Greenhaff PL. Creatine ingestion favorably affects performance and muscle metabolism during maximal exercise in humans. Am J Physiol Endocrinol Metab 271: E31-E37, 1996.

8. Craig NP and Norton KI. Characteristics of track cycling. Sports Med 31: 457-468, 2001.

9. Dahlstedt AJ, Katz A, and Westerblad H. Role of myoplasmic phosphate in contractile function of skeletal muscle: studies on creatine kinase-deficient mice. J Physiol 533: 379-388, 2001.

10. Fulco CS, Rock PB, and Cymerman A. Maximal and submaximal exercise performance at altitude. Aviat Space Environ Med 69: 793-801, 1998.

11. Gaitanos GC, Williams C, Boobis LH, and Brooks S. Human muscle metabolism during intermittent maximal exercise. J Appl Physiol 75: 712-719, 1993.

12. Granier P, Mercier B, Mercier J, Anselme F, and Prefaut C. Aerobic and anaerobic contribution to Wingate test performance in sprint and middle-distance runners. Eur $J \mathrm{Appl}$ Physiol 70: 58-65, 1995.

13. Green S, Dawson BT, Goodman C, and Carey MF. Anaerobic ATP production and accumulated $\mathrm{O}_{2}$ deficit in cyclists. Med Sci Sports Exerc 28: 315-321, 1996.

14. Harris RC, Hultman E, Kaijser L, and Nordesjo LO. The effect of circulatory occlusion on isometric exercise capacity and energy metabolism of the quadriceps muscle in man. Scand J Clin Lab Invest 35: 87-95, 1975.

15. He ZH, Bottinelli R, Pellegrino MA, Ferenczi MA, and Reggiani C. ATP consumption and efficiency of human single muscle fibers with different myosin isoform composition. Biophys $J$ 79: 945-961, 2000.

16. Jacobs I, Tesch PA, Bar-Or O, Karlsson J, and Dotan R. Lactate in human skeletal muscle after 10 and $30 \mathrm{~s}$ of supramaximal exercise. J Appl Physiol 55: 365-367, 1983.

17. Jones NL, McCartney N, Graham T, Spriet LL, Kowalchuk JM, Heigenhauser GJ, and Sutton JR. Muscle performance and metabolism in maximal isokinetic cycling at slow and fast speeds. J Appl Physiol 59: 132-136, 1985.

18. Kuipers H, Verstappen FT, Keizer HA, Geurten P, and van Kranenburg G. Variability of aerobic performance in the laboratory and its physiologic correlates. Int J Sports Med 6: 197$201,1985$.

19. Lopez Calbet JA, Armengol Ramos O, Chavarren Cabrero J, and Dorado Garcia C. An anthropometric equation for the determination of the percentage of body fat in young men from the Canarian population. Med Clin (Barc) 108: 207-213, 1997.

20. MacDougall JD, Hicks AL, MacDonald JR, McKelvie RS, Green HJ, and Smith KM. Muscle performance and enzymatic adaptations to sprint interval training. J Appl Physiol 84: 21382142, 1998.

21. Mackova E, Melichna J, Havlickova L, Placheta Z, Blahova D, and Semiginovsky B. Skeletal muscle characteristics of sprint cyclists and nonathletes. Int J Sports Med 7: 295-297, 1986.

22. McLellan TM, Cheung SS, and Meunier MR. The effect of normocapnic hypoxia and the duration of exposure to hypoxia on supramaximal exercise performance. Eur J Appl Physiol 66: 409-414, 1993.

23. McLellan TM, Kavanagh MF, and Jacobs I. The effect of hypoxia on performance during $30 \mathrm{~s}$ or $45 \mathrm{~s}$ of supramaximal exercise. Eur J Appl Physiol 60: 155-161, 1990.

24. Medbo JI and Burgers S. Effect of training on the anaerobic capacity. Med Sci Sports Exerc 22: 501-507, 1990.

25. Medbo JI, Mohn AC, Tabata I, Bahr R, Vaage O, and Sejersted OM. Anaerobic capacity determined by maximal accumulated $\mathrm{O}_{2}$ deficit. J Appl Physiol 64: 50-60, 1988.

26. Medbo JI and Tabata I. Relative importance of aerobic and anaerobic energy release during short-lasting exhausting bicycle exercise. J Appl Physiol 67: 1881-1886, 1989.

27. Noakes TD. Physiological models to understand exercise fatigue and the adaptations that predict or enhance athletic performance. Scand J Med Sci Sports 10: 123-145, 2000.

28. Parolin ML, Chesley A, Matsos MP, Spriet LL, Jones NL, and Heigenhauser GJ. Regulation of skeletal muscle glycogen phosphorylase and PDH during maximal intermittent exercise. Am J Physiol Endocrinol Metab 277: E890-E900, 1999.

29. Radegran G and Calbet JA. Role of adenosine in exerciseinduced human skeletal muscle vasodilatation. Acta Physiol Scand 171: 177-185, 2001.

30. Richardson RS, Noyszewski EA, Leigh JS, and Wagner PD. Lactate efflux from exercising human skeletal muscle: role of intracellular $\mathrm{PO}_{2}$. J Appl Physiol 85: 627-634, 1998.

31. Saltin B. Anaerobic capacity: past, present and prospective. In: Biochemistry of Exercise VII, edited by AW Taylor, Gollnick PD, Green HJ, Ianuzzo CD, Noble EG, Métivier G, and Sutton JR. Champaign, IL: Human Kinetics, 1990, p. 387-412.

32. Saltin B, Søndegaard H, Zacho M, van Hall G, and Calbet JAL. Blood gases, acid-base balance, muscle mass, and exercise capacity at the upper tolerable limit for humans of acute and chronic hypoxia. Blood Gas News 9: 6-10, 2000.

33. Spriet LL. Anaerobic metabolism during high-intensity exercise. In: Exercise Metabolism, edited by M Haargreaves. Champaign, IL: Human Kinetics, 1995, p. 1-39.

34. Sutton JR, Reeves JT, Wagner PD, Groves BM, Cymerman A, Malconian MK, Rock PB, Young PM, Walter SD, and Houston CS. Operation Everest II: oxygen transport during exercise at extreme simulated altitude. J Appl Physiol 64: 13091321, 1988.

35. Trump ME, Heigenhauser GJ, Putman CT, and Spriet LL. Importance of muscle phosphocreatine during intermittent maximal cycling. J Appl Physiol 80: 1574-1580, 1996.

36. Van Hall G, Calbet JA, Sondergaard H, and Saltin B. The reestablishment of the normal blood lactate response to exercise in humans after prolonged acclimatization to altitude. $J$ Physiol 536: 963-975, 2001.

37. Van Ingen Schenau GJ, de Koning JJ, and de Groot G. The distribution of anaerobic energy in 1000 and 4000 metre cycling bouts. Int J Sports Med 13: 447-451, 1992.

38. Westerblad H, Dahlstedt AJ, and Lannergren J. Mechanisms underlying reduced maximum shortening velocity during fatigue of intact, single fibres of mouse muscle. J Physiol 510: 269-277, 1998.

39. Weyand PG, Lee CS, Martinez-Ruiz R, Bundle MW, Bellizzi MJ, and Wright S. High-speed running performance is largely unaffected by hypoxic reductions in aerobic power. $J \mathrm{Appl}$ Physiol 86: 2059-2064, 1999.

40. Withers RT, Sherman WM, Clark DG, Esselbach PC, Nolan SR, Mackay MH, and Brinkman M. Muscle metabolism during 30, 60 and $90 \mathrm{~s}$ of maximal cycling on an air-braked ergometer. Eur J Appl Physiol 63: 354-362, 1991. 